\title{
Tolerância de gemas floríferas, flores e frutos de pessegueiro a temperaturas de ocorrência de geadas
}

\author{
Amanda da Fonseca Borges ${ }^{1}$, Tiago Madruga Telesca da Silveira ${ }^{2}$, Juliano dos Santos ${ }^{3}$, \\ Maria do Carmo Bassols Raseira**
}

\section{RESUMO}

Na região produtora de pêssegos do sul do Brasil, não é rara a ocorrência de geadas nos meses de julho, agosto e, em alguns anos, até setembro. Este período coincide com a floração do pessegueiro e com o início do desenvolvimento dos frutos. Com a finalidade de testar possíveis diferenças entre cultivares quanto à tolerância a baixas temperaturas foram conduzidos experimentos, em delineamento inteiramente casualizado, nos anos de 2009 e 2010. Foram testados dois fatores (genótipo e estádio da gema floral), com três repetições e 20 botões forais por parcela. Os genótipos testados foram os cultivares 'Chimarrita', 'Coral' e ‘BR-1' e a seleção Cascata 730. Em 2010, foi acrescentado o cv. 'Charme’. Os estádios fenológicos testados foram: o de botão prateado, botão rosado, balão e flor aberta. Ramos destacados dos genótipos a serem testados foram submetidos, por 16 horas, a temperaturas entre $-2,2$ e $-5,5^{\circ} \mathrm{C}$. Ramos com frutos, antes e após o endurecimento do caroço, foram testados em outro experimento. As diferenças entre genótipos foram pequenas e parecem estar mais ligadas ao pré-condicionamento das gemas. A seleção Cascata 730 mostrou ser das mais sensíveis ao frio. As gemas florais são, geralmente, menos sensíveis a temperaturas negativas (próximas a $-3^{\circ} \mathrm{C}$ ), nos estádios de botão rosado e balão. Frutos com endocarpo macio são sensíveis a danos de frio, independentemente do genótipo. Temperaturas próximas a $2{ }^{\circ} \mathrm{C}$ negativos não causam problemas em frutos com endocarpo já endurecido.

Palavras-chave: tolerância a geadas, estádios fenológicos, genótipos.

\section{ABSTRACT}

\section{Tolerance of peach buds and fruits to frost temperatures}

Frosts are not rare in the peach production region of Southern Brazil, during the months of July, August and, in some years, even in September. This period coincides with peach blooming and initial fruit development. Aiming to test possible difference among peach genotypes regarding tolerance to low temperatures, two completely randomized experiments were set up in 2009 and 2010. Two factors were tested (genotype and flower bud development stage) using three replications and 20 flower buds per plot. The genotypes included cultivars Chimarrita, Coral and BR-1 and the selection Cascata 730. In the 2010 trial, cv. Charme was added. The phenological stages tested were silver bud, pink, balloon and opened flower. Detached twigs from the genotypes to be studied were submitted during 16 hours to temperatures between $-2,2$ and $-5,5^{\circ} \mathrm{C}$. Twigs with fruits before and after pit hardening stage were tested in another experiment. Differences among genotypes were small and seemed to be more dependent on preconditioning of the bud.

Recebido para publicação em 29/12/2011 e aprovado em 08/05/2012

${ }^{1}$ Graduanda em Agronomia. Faculdade de Agronomia Eliseu Maciel, Universidade Federal de Pelotas, Rua Gomes Carneiro, 01, Centro, Campus Capão do Leão, 96010-610, Pelotas, Rio Grande do Sul, Brasil. amanda.fb@hotmail.com

${ }^{2}$ Engenheiro-Agrônomo, Mestre. Doutorando em Fitotecnia, Faculdade de Agronomia, Universidade Federal do Rio Grande do Sul, Av. Bento Gonçalves, 9500, 91509-900, Porto Alegre, Rio Grande do Sul, Brasil. telesca.tiagro@gmail.com

${ }^{3}$ Biólogo, Doutor. Embrapa Clima Temperado, BR 392, Km 78, Caixa Postal 403, 96010-971, Pelotas, Rio Grande do Sul, Brasil. julianopatologia@gmail.com

${ }^{4}$ Engenheira-Agrônoma, Doutora. Bolsista CNPq, Embrapa Clima Temperado, BR 392, Km 78, Caixa Postal 403, 96010-971, Pelotas, Rio Grande do Sul, Brasil. maria.bassols@cpact.embrapa.br (*Autora para correspondência). 
However, the selection Cascata 730 seemed to be more sensitive to these temperatures. The flower buds were generally less sensitive to negative temperatures (around $-3{ }^{\circ} \mathrm{C}$ ) on the pink and balloon stages. Soft endocarp fruits were sensitive to cold damage regardless the genotype. Temperatures around $-2{ }^{\circ} \mathrm{C}$ do not cause damage on fruits when the endocarp is already hard.

Key words: frost tolerance; phenologic stages, genotypes.

\section{INTRODUÇÃO}

A literatura faz várias referências a danos pelo frio (cold hardiness), em pessegueiro, e as diferenças entre cultivares, quanto à tolerância a este aspecto (Layne et al., 1977; Cain \& Andersen, 1980; Layne, 1982; Layne, 1984). Em áreas com clima tipicamente temperado, não é raro que estes estudos refiram-se a temperaturas inferiores a $20{ }^{\circ} \mathrm{C}$ negativos. Mesmo nas regiões produtoras mais frias do Brasil, não ocorrem essas temperaturas. Entretanto, podem ocorrer temperaturas negativas e geadas na floração, ou mesmo, após, no período de desenvolvimento dos frutos.

Vários métodos são utilizados para avaliar a tolerância de diferentes genótipos a essas condições, sendo a avaliação após os chamados "invernos testes" um dos mais comuns. Assmann et al. (2008) avaliaram 28 genótipos de pessegueiro, em diferentes estádios fenológicos, com base nos danos ocorridos após geada tardia, com temperatura de $1,06{ }^{\circ} \mathrm{C}$ negativo. Já Raseira et al. (1992) e Borges et al. (2009) testaram seleções e cultivares de pessegueiro, submetendo-os a condições controladas.

Com o objetivo de avaliar a incidência de danos causados por temperaturas negativas, foram realizados testes com ramos destacados de pessegueiro, submetidos a frio por 16 horas.

\section{MATERIAL E MÉTODOS}

Os testes foram realizados, por dois anos consecutivos (2009 e 2010), no Laboratório de Melhoramento Vegetal, na Embrapa Clima Temperado, Pelotas, Rio Grande do Sul, sendo utilizados, em 2009, ramos da seleção Cascata 730 e dos cultivares 'Chimarrita', 'BR1' e 'Coral'. Em 2010, usaram-se os mesmos cultivares e seleção do ano anterior, mais o cv. 'Charme'. Em ambos os anos de estudo, utilizou-se a metodologia descrita por Raseira et al. (1992). O delineamento experimental foi inteiramente casualizado, com dois fatores (genótipo e estádio de desenvolvimento), em três repetições e 20 botões florais por repetição e por estádio de desenvolvimento da gema floral (botão prateado, botão rosado, balão e flor aberta). Ramos destacados dos cultivares e da seleção em estudo foram acondicionados em frascos com água e submetidos, por um período de 16 horas, às baixas temperaturas e, após esse tempo, colocados à temperatura ambiente $\left( \pm 20^{\circ} \mathrm{C}\right)$, por no mínimo 24 horas, para então serem avaliados. A avaliação foi realizada com base nos danos ao ovário da flor. Os pistilos foram cortados longitudinalmente e considerados danificados aqueles que se apresentavam escurecidos. Ramos com frutos, antes e após o endurecimento do endocarpo, foram, também, submetidos aos mesmos procedimentos. Foi usado delineamento experimental totalmente casualizado, com cinco repetições, sendo cada parcela de \pm 15 frutos. Os ramos com os frutos foram colocados em frascos com água e submetidos, em câmara fria, às temperaturas negativas, por um período de 16 horas. Após, foram retirados da câmara e mantidos em temperatura ambiente, de um dia para o outro. Decorrido esse tempo, com uma tesoura de poda, os frutos (mesocarpo e endocarpo, ou seja, polpa e caroço) foram cortados transversalmente. Foram avaliadas polpa e semente, definindo-se se tinham aspecto normal, parcialmente danificado ou totalmente danificado. Foram considerados totalmente danificados quando havia escurecimento interno da semente.

A variação de temperatura sofrida não foi a mesma entre os diferentes genótipos. Os ramos da seleção Cascata 730 e de 'Chimarrita', em 2009, ficaram sob temperaturas que variaram entre $3,5^{\circ} \mathrm{C}$ e $5,5^{\circ} \mathrm{C}$ negativos; os de 'BR-1' e 'Coral', entre $1,1^{\circ} \mathrm{C}$ e $3,5^{\circ} \mathrm{C}$ negativos. Em 2010, Cascata 730 e 'Chimarrita' foram mantidos em temperaturas que variaram entre $1,6^{\circ} \mathrm{C}$ e $3,9^{\circ} \mathrm{C}$ negativos, enquanto 'BR-1' e 'Coral' ficaram entre $1,5^{\circ} \mathrm{C}$ e $4,0^{\circ} \mathrm{C}$ negativos e, os ramos de 'Charme', entre $1,5^{\circ} \mathrm{C}$ e $4,5^{\circ} \mathrm{C}$ negativos. É importante salientar que, por causa dessa variação, o período em horas, ao qual cada genótipo ficou exposto a temperaturas de $3{ }^{\circ} \mathrm{C}$ negativos ou menos, também variou. No caso de ramos com frutos, estes foram mantidos entre $-1,8^{\circ} \mathrm{C}$ e $-5,3^{\circ} \mathrm{C}$.

Os dados foram submetidos à análise de variância, transformando-se as percentagens de danos para cada unidade experimental para arc sen $\sqrt{x} / 100$, a fim de se obter uma distribuição normal dos dados. As médias foram comparadas pelo teste de Tukey a 5\%. Para a análise conjunta dos dados, foi também verificada a homogeneidade das variâncias dos dois anos, avaliados pelo teste de Cochran. 


\section{RESULTADOS E DISCUSSÃO}

As diferenças obtidas em 2009, para danos em flores e gemas florais, foram significativas para genótipos, para estádios de desenvolvimento e para a interação entre estes dois fatores. O cv. 'Coral' foi o que apresentou menor percentagem de botões florais danificados em todos os estádios, exceto botão prateado, não diferindo de 'BR-1', e nas fases de botão rosado e balão não diferindo também da seleção Cascata 730. Os cultivares 'Chimarrita' e 'BR1' tiveram danos semelhantes, independentemente do estádio de desenvolvimento das gemas florais. A seleção Cascata 730 sofreu maiores danos em flores abertas, enquanto, para o cv. 'Coral', a maior percentagem de danos foi verificada no estádio de botão prateado (Tabela 1).

Em 2010, não houve diferenças entre os percentuais de danos nos diferentes genótipos, nem a interação entre genótipo e estádio de desenvolvimento do botão floral foi significativa. Houve diferenças entre os estádios, sendo mais sensíveis aos danos por frio os estádios de botão prateado e de flor aberta (Tabela 2).

Como as variâncias dos dois anos foram homogêneas, foi feita a análise conjunta dos anos para os quatro genótipos comuns, seleção Cascata 730 e cultivares 'BR1', 'Coral' e 'Chimarrita'.

Foram significativas as interações ano e genótipo; ano e estádio fenológico e genótipo e estádio fenológico. No geral, as diferenças entre genótipos não foram significativas, em 2010, ficando as percentagens de danos entre 49 e 66\%, enquanto, em 2009, o cv. ‘Coral’ foi melhor que os demais, mas não diferiu significativamente do cv. 'BR1' (Tabela 3). Os estádios de botão rosado e balão foram os menos sensíveis ao frio, embora, em 2009, o estádio de balão não tenha diferido do botão prateado (Tabela 4). A seleção Cascata 730 foi mais sensível na flor recém-aberta, enquanto o cv. 'Coral' sofreu mais danos no estádio de botão prateado (Tabela 5).

A percentagem de danos foi a mesma nos dois anos testados, para o cv. 'BR1'; entretanto, isto não pode ser explicado apenas pelo fato de a temperatura na câmara ter- se mantido igual, uma vez que o mesmo resultado não foi obtido com o cv. 'Coral', que teve maior percentagem de danos em 2010. É sabido que o pré-condicionamento das gemas tem influência na sua tolerância ao frio. Verificando-se as datas de floração e as médias das temperaturas mínimas, nos dias que antecederam o tratamento com temperaturas negativas, foram mais altas, em 2010 (Tabela 6), o que pode explicar os resultados verificados com o cv. 'Coral'. Entretanto, o mesmo ocorreu em relação ao cv. 'BR1' e este não foi afetado da mesma forma. Seria interessante que fossem realizadas observações sobre a influência do pré-condicionamento ao frio, em "invernos testes”, utilizando-se diversos genótipos, pois a menor influência do pré-condicionamento poderia indicar uma melhor adaptação a áreas com oscilações de temperatura.

O cultivar ‘Chimarrita’ sofreu mais danos em 2009, mas nesse ano as temperaturas na câmara fria foram menores, conforme mencionado na seção Material e Métodos. Já a seleção Cascata 730 foi igualmente sensível, apesar das

Tabela 1. Percentual de danos em flores de quatro genótipos de pessegueiro, em diferentes estádios de desenvolvimento, no ano de 2009

\begin{tabular}{lcccr}
\hline \multirow{2}{*}{ Genótipos } & \multicolumn{5}{c}{ Estádios } \\
\cline { 2 - 5 } & BP & BR & B & FA \\
\hline Cascata 730 & 61,67 a B & 58,33 ab B & 66,67 ab AB & 100,00 a A \\
Chimarrita & 85,00 a A & 63,33 a A & 83,33 a A & 96,67 a A \\
BR1 & 55,56 a A & 42,21 ab A & 42,22 bc A & 60,00 b A \\
Coral & 73,34 a A & 31,11 b B & 24,43 c B & 37,78 b B \\
\hline
\end{tabular}

* $\mathrm{BP}=$ botão prateado, $\mathrm{BR}$ = botão rosado, $\mathrm{B}=$ balão, $\mathrm{FA}=$ flor aberta.

Médias seguidas pela mesma letra minúscula, nas colunas, e, maiúscula, nas linhas, não diferem entre si pelo teste de Tukey ( $\alpha=0,05$ ).

Tabela 2. Percentual de danos em flores de pessegueiro, em diferentes estádios de desenvolvimento, no ano de 2010

\begin{tabular}{lccccc}
\hline \multirow{2}{*}{ Genótipos } & \multicolumn{5}{c}{ Estádios } \\
\cline { 2 - 6 } & BP & BR & B & FA & Total \\
\hline Cascata 730 & 75,00 & 35,00 & 46,67 & 90,00 & 61,67 Ns \\
Chimarrita & 73,33 & 33,33 & 23,33 & 66,67 & 49,17 \\
BR1 & 88,33 & 40,00 & 26,67 & 66,67 & 55,42 \\
Coral & 90,00 & 61,67 & 50,00 & 65,00 & 66,67 \\
Charme & 70,00 & 76,67 & 50,00 & 86,67 & 70,83 \\
\hline Total & $79,33 \mathrm{~A}$ & $49,33 \mathrm{~B}$ & $39,33 \mathrm{~B}$ & $75,00 \mathrm{~A}$ &
\end{tabular}

* $\mathrm{BP}=$ botão prateado, $\mathrm{BR}=$ botão rosado, $\mathrm{B}=$ balão, $\mathrm{FA}=$ flor aberta

Médias seguidas pela mesma letra maiúscula nas linhas não diferem entre si pelo teste de Tukey $(\alpha=0,05)$. NS = não significativo. 
temperaturas de 2010 não terem sido tão baixas quanto as do ano anterior. Szalay et al. (2000), estudando locais e cultivares diferentes quanto à tolerância a temperaturas de congelamento, não encontraram diferenças significativas entre locais e não houve mudanças quanto à tolerância dos cultivares. As gemas foram avaliadas, usando-se testes artificiais de congelamento e determinando-se a percentagem de $50 \%$ de morte de gemas para cada cultivar e data amostrada.

Tabela 3. Percentual de danos em flores de quatro genótipos de pessegueiro em cada ano de produção

\begin{tabular}{lcl}
\hline \multirow{2}{*}{ Genótipos } & \multicolumn{2}{c}{ Safra } \\
\cline { 2 - 3 } & $\mathbf{2 0 0 9}$ & \multicolumn{1}{c}{$\mathbf{2 0 1 0}$} \\
\hline Cascata 730 & 71,67 a A & 61,66 ab A \\
Chimarrita & 82,08 a A & 49,16 b B \\
BR1 & 50,00 b A & 55,41 ab A \\
Coral & 41,67 b B & 66,66 a A \\
\hline
\end{tabular}

Médias seguidas pela mesma letra minúscula, nas colunas, e, maiúscula, nas linhas, não diferem entre si pelo teste de Tukey $(\alpha=0,05)$.

Tabela 4. Percentual de danos em flores de pessegueiro, em diferentes estádios de desenvolvimento

\begin{tabular}{|c|c|c|}
\hline \multirow{2}{*}{ Estádios } & \multicolumn{2}{|c|}{ Safra } \\
\hline & 2009 & 2010 \\
\hline Botão prateado & 68,89 ab B & 81,67 a $A$ \\
\hline Botão rosado & 48,75 с A & $42,50 \mathrm{~b} \mathrm{~A}$ \\
\hline Balão & 54,16 bc $A$ & 36,67 b B \\
\hline Flor aberta & 73,61 a $\mathrm{A}$ & 72,08 a $A$ \\
\hline
\end{tabular}

Médias seguidas pela mesma letra minúscula, nas colunas, e, maiúscula, nas linhas não diferem entre si pelo teste de Tukey $(\alpha=0,05)$.
Os resultados obtidos, quanto aos estádios dos botões florais mais sensíveis aos danos de frio, corroboram aqueles de Raseira et al. (1992); entretanto, estes autores concluíram que os cvs. 'Coral’ e 'BR1’ eram mais sensíveis ao frio que o cv. 'Chimarrita', o que não se confirmou neste trabalho. Esta divergência pode ser explicada porque, nos testes daqueles autores, as temperaturas em que foram mantidos os cvs. 'Coral' e 'BR1' foram mais baixas, enquanto neste trabalho o cv. 'Chimarrita’ ficou em temperatura mais baixa, em 2009. No ano seguinte, quando as condições não diferiram muito entre os genótipos, 'Chimarrita' foi melhor que 'Coral', o que confirma, pelo menos, para estes dois cultivares, os resultados daqueles autores. Há que ser considerado, também, o tamanho das amostras utilizadas, pois segundo Pedryc et al. (1999), amostras contendo 200 gemas dão resultados confiáveis em relação à tolerância a geadas. Maiores amostras diminuem os desvios, mas não são proporcionais ao trabalho envolvido no experimento. No presente caso, considerando-se as gemas florais, independentemente do estádio de desenvolvimento, foram utilizadas 80 gemas por repetição e um total de 240 gemas por cultivar. Assim, os resultados em relação ao cultivar, podem ser considerados de boa confiabilidade.

No ano de 2009, para danos nos frutos, foram utilizados apenas ramos com frutos após o endurecimento do endocarpo, resultando em ausência de danos. Em 2010, foram realizados dois ensaios, utilizando-se ramos com frutos, sendo um deles com frutos antes do endurecimento do endocarpo e, outro, após o endurecimento.

Para frutos com endocarpo ainda macio, não houve diferenças significativas entre genótipos (Seleção Casca-

Tabela 5. Percentual de danos em flores de pessegueiro em diferentes estádios e genótipos, nos anos de 2009 e 2010

\begin{tabular}{|c|c|c|c|c|}
\hline \multirow{2}{*}{ Genótipos } & \multicolumn{4}{|c|}{ Estádios* } \\
\hline & $\mathbf{B P}$ & BR & B & FA \\
\hline Cascata 730 & 68,33 а $\mathrm{B}$ & 46,67 а B & 56,67 а B & 95,00 a $\mathrm{A}$ \\
\hline Chimarrita & 79,17 a $A$ & 48,33 а B & 53,33 a $B$ & 81,66 ab A \\
\hline BR1 & 71,94 a A & 41,10 a BC & 34,44 a $C$ & 63,33 bc $\mathrm{AB}$ \\
\hline Coral & 81,67 a $\mathrm{A}$ & 46,39 а B & 37,22 a $B$ & 51,39 с В \\
\hline
\end{tabular}

* BP = botão prateado, BR = Botão rosado, B = balão, FA = flor aberta

Médias seguidas pela mesma letra minúscula, nas colunas, e, maiúscula, nas linhas não diferem entre si pelo teste de Tukey ( $\alpha=0,05)$.

Tabela 6. Temperaturas médias diárias $\left({ }^{\circ} \mathrm{C}\right)$ ocorridas nos dias que antecederam aos tratamentos a que foram submetidos os cvs. 'Coral' e 'BR1', nos anos de 2009 e 2010

\begin{tabular}{lcccccc}
\hline & $\mathbf{2 0 0 9}$ & & & \multicolumn{2}{c}{$\mathbf{2 0 1 0}$} \\
\cline { 1 - 3 } \cline { 5 - 6 } Médias & Máximas & Mínimas & & Médias & Máximas & Mínimas \\
\hline 16,1 & 24,1 & 10,2 & & 18,1 & 23,4 & 15,3 \\
20,4 & 31,0 & 11,9 & & 18,7 & 25,4 & 10,6 \\
24,8 & 31,4 & 16,7 & & 12,9 & 16,8 & 09,2 \\
12,4 & 16,7 & 09,7 & & 17,4 & 19,5 & 14,7 \\
11,7 & 15,1 & 09,5 & & 16,8 & 17,5 & 16,2 \\
12,8 & 13,6 & 10,8 & & 16,8 & 17,4 & 16,0 \\
11,6 & 13,0 & 10,6 & & 17,3 & 19,0 & 16,2 \\
\hline
\end{tabular}

Rev. Ceres, Viçosa, v. 59, n.3, p. 355-359, mai/jun, 2012 
ta 730, cvs. 'BR1', 'Coral’ e 'Chimarrita') nem entre anos. Após o endurecimento do endocarpo, houve apenas 11\% de dano nos frutos da seleção Cascata 730 e 3\% nos frutos do cv. 'Chimarrita', não havendo nenhum dano nos demais genótipos. Esta observação está de acordo com os resultados obtidos por Assmann et al. (2008), que concluíram, com base na observação de 28 genótipos, após ocorrência de geada, que frutos com diâmetro sutural de 3 cm (e que portanto já deveriam ter o endocarpo endurecido) apresentaram boa tolerância ao frio, independentemente do genótipo avaliado.

Não foram analisados os dados das flores, em comparação com os dos frutos, mas, por observação, pode-se inferir que, para os quatro genótipos citados acima, a geada na floração só seria mais prejudicial que a geada nos frutos antes do endurecimento do caroço, se a grande maioria das gemas estiver em estádio de botão prateado ou em flor aberta. Além disso, uma geada após o endurecimento do endocarpo não causaria perda significativa na quantidade de frutos produzidos.

Quando se analisam os resultados aqui obtidos, em comparação com os obtidos por Raseira et al. (1992), podese inferir que temperaturas de $1^{\circ} \mathrm{C}$ negativo e superiores a $3{ }^{\circ} \mathrm{C}$ negativos não causam perda total de flores. Portanto, como as geadas na região ocorrem com temperaturas pouco inferiores a $1{ }^{\circ} \mathrm{C}$ negativo, e como o período de floração nesta região é relativamente amplo, existem flores em diversos estádios de desenvolvimento quando ocorre uma geada. Assim, salvo em situações muito especiais, de vários dias consecutivos com geadas fortes ou de temperaturas próximas a 4 ou $5{ }^{\circ} \mathrm{C}$ negativos, a ocorrência de geada na floração dos genótipos em estudo resultaria em um forte e antecipado raleio de frutos, podendo, ou não, resultar em redução de produtividade do pomar, uma vez que o número menor de frutos seria, pelo menos em parte, compensado por seu tamanho. Por outro lado, o custo com raleio e com colheita seria reduzido e, o preço de mercado, possivelmente, mais alto.

\section{CONCLUSÕES}

As diferenças entre genótipos são pequenas, em relação à sensibilidade ao frio e parecem estar mais ligadas ao pré-condicionamento das gemas. Apesar disso, a seleção Cascata 730 mostra ser das mais sensíveis ao frio.

As gemas florais são menos sensíveis a temperaturas negativas (próximas a $3{ }^{\circ} \mathrm{C}$ negativos), nos estádios de botão rosado e balão.

Frutos com endocarpo macio são sensíveis a danos de frio, independentemente do genótipo.

Temperaturas próximas a $2{ }^{\circ} \mathrm{C}$ negativos não causam problemas em frutos com endocarpo já endurecido.

\section{REFERÊNCIAS}

Assman AP, Citadin I, Locatelli MC, Scariot S, Danner MA \& Raseira MCB (2008) Tolerância de frutos de pessegueiro a geadas. Revista Brasileira de Fruticultura, 30:1030-1035.

Borges AF, Silveira TT \& Raseira MCB (2009) Efeito de baixas temperaturas nos diferentes estádios florais de pessegueiro (Prunus persica). In: XVIII Congresso de Iniciação Cientifica/ UFPel, Pelotas/RS. Anais... CD-ROM.

Cain DW \& Andersen RL (1980) Inheritance of wood hardiness among hybrids of commercial and wild Asian peach genotypes. Journal of the American Society for Horticultural Science, 105:349-354.

Layne REC, Jackson HO \& Stroud FD (1977) Influence of peach seedling rootstocks on defoliation and cold hardiness of peach cultivars. Journal of the American Society for Horticultural Science, 102:89-92.

Layne REC (1982) Cold hardiness of peaches and nectarines following a test winter. Fruit Varieties Journal, 36:90-98.

Layne REC (1984) Breeding peaches in North America for cold hardiness and perennial canker (Leucostoma spp.) resistance: review and outlook. Fruit Varieties Journal, 38:130-136.

Pedryc A, Korbuly J \& Szabo Z (1999) Artificial frost treatment methods of stone fruits. Acta Horticulturae, 488:377-380.

Raseira MCB, Silva JB, Herter F \& Peters JA (1992) Sensibilidade de gemas floríferas de pessegueiro, Prunus persica L. Batsch, ao frio. Revista Brasileira de Fruticultura, 14:167-172.

Szalay L, Papp J \& Szaóbo Z (2000) Evaluation of frost tolerance of peach varieties in artificial freezing tests. Acta Horticulturae, 538:407-410. 